When 2 is subjected to hydrolysis-decarboxylation in boiling, dilute $\mathrm{HCl}$, a 35-40\% yield of the title compound 5 is obtained after separation of polymeric material.

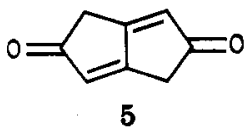

Compound 5 is a very pale yellow crystalline substance: ${ }^{3}$ mp 240-242 ${ }^{\circ} \mathrm{C} ;{ }^{10}{ }^{1} \mathrm{H}$ NMR $\delta 3.28(\mathrm{~s}, 4 \mathrm{H}), 6.36$ (s, $2 \mathrm{H}$ ); ${ }^{13} \mathrm{C}$ NMR 36.4, 128.1, 172.2, 202.9; mass spectrum, $m / e$ (relative intensity) $134\left(\mathrm{M}^{+}, 100\right), 106(23), 78(73), 67\left(\mathrm{M}^{2+}\right.$, 14); UV-vis $\lambda_{\max } 270 \mathrm{~nm}(\epsilon 27000), 310 \mathrm{sh}(170)$.

The chemistry of 5 so far investigated parallels in many respects that of 4-cyclopentene-1,3-dione:11 it is essentially nonenolic, unstable in contact with base, and reactive toward diazonium ion. The methylene hydrogens exchange readily with deuterium as shown by the disappearance of the $\delta 3.28$ peak in the NMR. Under rigorously dry and oxygen-free conditions, a solution of potassium tert-butoxide in tert-butyl alcohol was added to a solution of 5 in tert-butyl alcohol. An immediate deep purple solution was formed, which rapidly changed to brown. No clearly defined NMR absorption was observed. ${ }^{12}$

Attempts to form an enol derivative by using isopropenyl acetate did not yield an identifiable product. The bis(tosylhydrazone) $\mathbf{6}$ of 5 forms readily in nearly quantitative yield in acidified methanol solution, precipitating analytically pure as bright yellow, feathery crystals. ${ }^{3} \mathrm{Com}$ pound 6 is highly insoluble in organic solvents but dissolves readily in aqueous $\mathrm{NaOH}$ solution.

Attempts to obtain pentalene by vacuum pyrolysis or photolysis of the dilithium salt of 6 failed. Treatment of a suspension of 6 in ether with methyllithium ${ }^{13,14}$ under nitrogen was also unsuccessful with nearly quantitative recovery of 6 .

Photolysis of a solution of 6 in aqueous $\mathrm{NaOH}$ with Sylvania "Daylight" fluorescent lamps produced 3-diazabicyclo[3.3.0]octa-1,5,7-triene (7). To avoid photolysis of

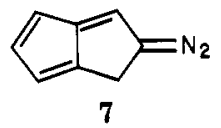

7 it was necessary to remove it as it formed by a vacuum steam distillation at $40-45^{\circ} \mathrm{C}$. Compound 7 was extracted from the distillate with pentane. Removal of the pentane under reduced pressure left a photolabile, orange red semisolid:15 IR (argon matrix) 2090, $2080 \mathrm{~cm}^{-1}$; mass spectrum, $m / e$ (relative intensity) $130(96), 102(100), 76$ (39); ${ }^{1} \mathrm{H} \mathrm{NMR}$ (at $-20^{\circ} \mathrm{C}, \mathrm{CDCl}_{3}$ ) $\delta 3.26-3.28(\mathrm{~m}, 2 \mathrm{H}$ ), 6.55-6.74 (m, $4 \mathrm{H})$.

Treatment of 5 with zinc dust in tetrahydrofuran-acetic acid (100:1, v/v) yields bicyclo[3.3.0]octa-1(5)-ene-3,7-dione (8) as white needles: mp 208-215 dec; ${ }^{3}{ }^{1} \mathrm{H}$ NMR $\delta 3.0(\mathrm{~s})$; ${ }^{13} \mathrm{C}$ NMR 42.3, 138.5, 214.5; mass spectrum, $\mathrm{m} / \mathrm{e} 136\left(\mathrm{M}^{+}\right.$, 47), 108 (61), 80 (37), 79 (100).

Compound 8 is stable in crystalline form and in dry aprotic solvents. However, its solutions, in methanol for

(10) This compound has also been isolated by Dr. S. H. Bertz from the hydrolysis-decarboxylation (and adventitious oxidation) of 1 (ref 8a).

(11) C. H. DePuy and P. R. Wells, J. Am. Chem. Soc. 82, 2909 (1960), and earlier papers.

(12) We are indebted to Dean Kahl and J. I. Brauman, Stanford University, for the tert-butoxide experiments.

(13) R. H. Shapiro and M. J. Heath, J. Am. Chem. Soc., 89, 5734 (1967)

(14) G. Kaufman, F. Cook, J. Schechter, J. Bayless, and L. Friedman, ibid., 89, 5736 (1967).

(15) We are indebted to O. L. Chapman and his associates at Iowa State University and the University of California at Los Angeles for these spectral analyses.

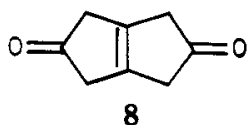

example, quickly become yellow, presumably due to a shift of the double bond to the conjugated position. ${ }^{16}$

Other aspects of the chemistry and photochemistry of the title compound and its derivatives are being investigated.

Acknowledgment. This work was supported in part by grants from Research Corporation, National Science Foundation, and the Petroleum Research Fund, administered by the American Chemical Society. We are grateful to the following for technical assistance: while students at Luther College, W. R. Bartlett, J. A. Duncan, J. Jorgensen, D. Lokensgard, L. C. Quass, D. Reasa, and K. Way; to M. L. M. Schilling (Bell Labs) for the ${ }^{13} \mathrm{C}$ NMR of 5; to J. M. Beard and W. Robbins. Particular thanks are due to O. L. Chapman and R. H. Eastman for helpful discussions and use of research facilities.

Registry No. 1, 78698-09-6; 2, 78698-10-9; 3, 68703-09-3; 4, 74513-16-9; 5, 78698-11-0; 6, 78698-12-1; 7, 78698-13-2; 8, 78698-14-3; dimethyl bromomalonate, 868-26-8.

Supplementary Material Available: Detailed experimental directions for the preparation of compounds 2 and 5 ; more complete IR and UV spectra for compounds $2,5,7$, and 8 (2 pages). Ordering information is given on any current masthead page.

(16) The conjugated isomer has been prepared by Dr. S. H. Bertz (ref 8a); it turns yellow immediately upon exposure to oxygen.

Adrian M. Docken

Department of Chemistry Luther College

Decorah, Iowa 52101

Received June 2, 1981

\section{Zinc Chloride Catalyzed Addition Reactions of Propargyl Chlorides with Acyclic 1,3-Dienes}

Summary: Zinc chloride catalyzed reactions of propargyl chlorides with acyclic 1,3 -dienes (at $-78^{\circ} \mathrm{C}$ ) give linear addition products, which cyclize to 4-(chloroalkylidene)cyclohexenes at elevated temperature.

Sir: In a theoretical analysis of Lewis acid catalyzed additions of alkyl halides RX to olefins (eq 1), we came to

$$
R x+>c=c<\frac{\text { Lewis }}{\text { acid }} \operatorname{RCCX}
$$

the conclusion that the formation of $1: 1$ products is only possible when the initial carbenium ions $\mathrm{R}^{+}$are better stabilized than the carbenium ions $\mathrm{RCC}^{+}$formed in the addition step. ${ }^{1}$ Solvolysis rates of alkyl chlorides were employed to predict whether a certain addition reaction is feasible or not.

In this communication we report Lewis acid catalyzed additions of propargyl chlorides to acyclic 1,3-dienes as an example for the application of these rules in planning syntheses.

(1) Mayr, H. Angew. Chem., Int. Ed. Engl. 1981, 20, 184. 


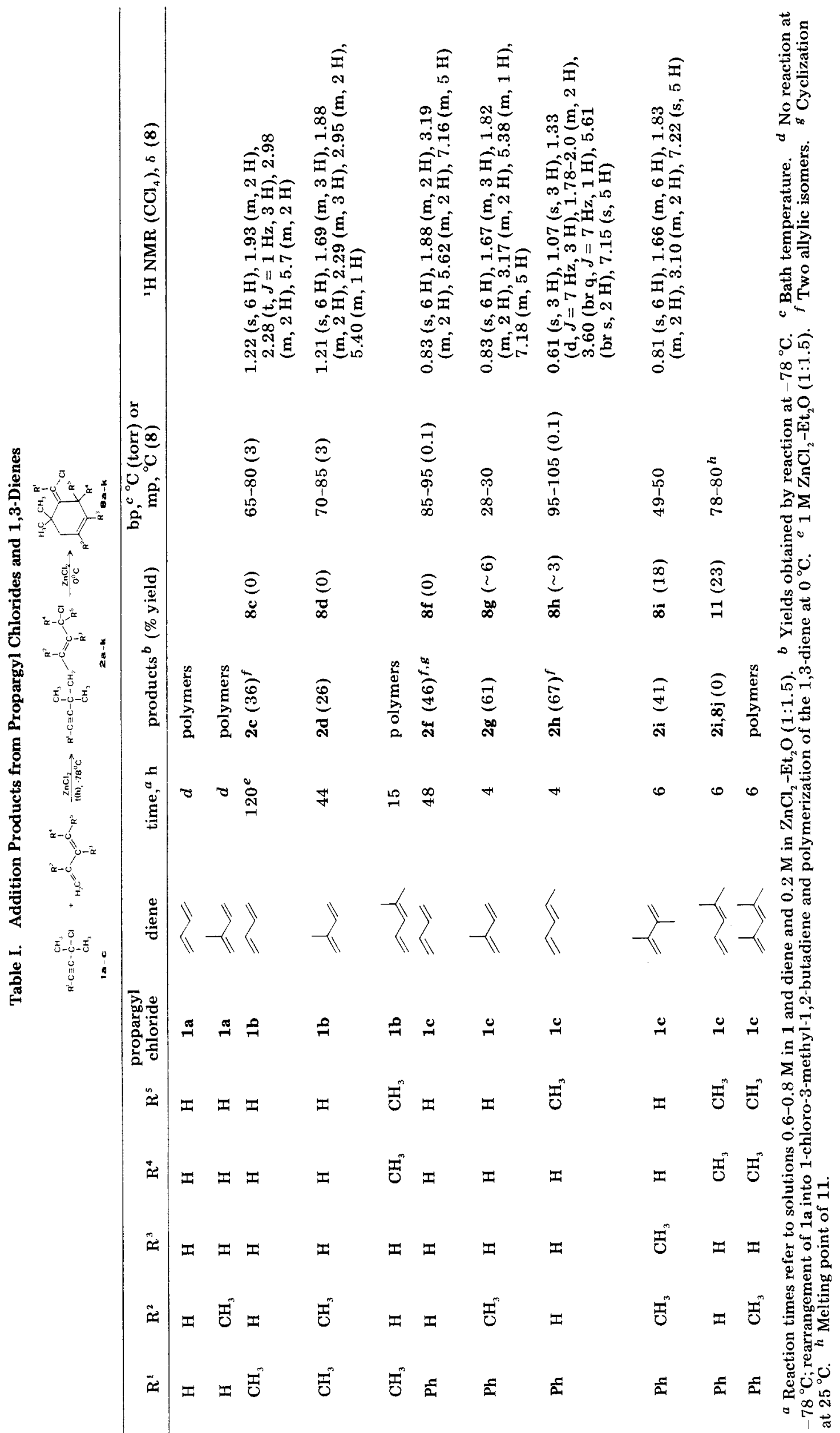


Scheme I

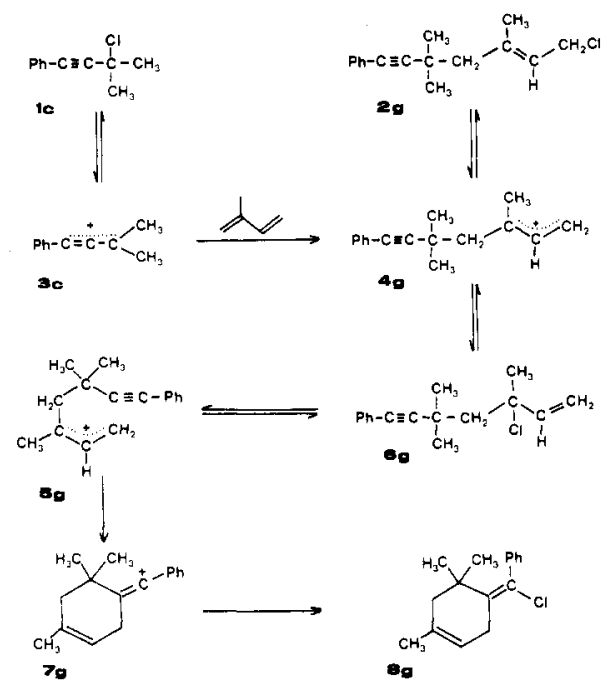

A typical reaction sequence is illustrated in Scheme . $^{2}$ When an equimolar mixture of propargyl chloride 1c and isoprene is treated with the homogeneous catalyst system $\mathrm{ZnCl}_{2}-\mathrm{Et}_{2} \mathrm{O}$ in dichloromethane at $-78^{\circ} \mathrm{C}$, the allyl chloride $2 \mathrm{~g}$ is obtained in $67 \%$ yield, contaminated by a small amount of $8 \mathrm{~g}$. Complete rearrangement of $2 \mathrm{~g}$ to $8 \mathrm{~g}$ takes place when the reaction mixture is allowed to warm up to $0^{\circ} \mathrm{C}$. Both products can be identified on the basis of their ${ }^{1} \mathrm{H}$ NMR spectra; ${ }^{3} 8 \mathrm{~g}$ reacts slowly with silver trifluoroacetate to yield the corresponding vinyl trifluoroacetate, which gives 4 -benzoyl-1,5,5-trimethylcyclohexene $(9)^{4}$ on hydrolysis.

As indicated in Scheme I, the initially formed allenyl cation 3c attacks isoprene at C-1, affording the 1,1-dialkylallyl cation $4 \mathrm{~g}^{5 \mathrm{a}}$, the precursor of allyl chlorides $\mathbf{2 g}$ and $6 \mathrm{~g}$. Presumably $2 \mathrm{~g}$ and $6 \mathrm{~g}$ equilibrate at $-78^{\circ} \mathrm{C}$ in the presence of $\mathrm{ZnCl}_{2}$, so that only the thermodynamically more stable isomer $\mathbf{2 g}$ is observed when the catalyst is washed out at low temperature. At elevated temperature $\mathrm{ZnCl}_{2}$-initiated redissociation of $2 \mathrm{~g}$ to $4 \mathrm{~g}$ takes place. Stereomutation of allyl cation $4 \mathrm{~g}$ via $6 \mathrm{~g}$ yields the $Z$ isomer $\mathbf{5 g}$, which has the proper configuration for $\pi$ cyclization to afford vinyl cation $\mathbf{7 g}{ }^{.5}$ Finally, addition of $\mathrm{Cl}^{-}$from the sterically less hindered side produces vinyl chloride $8 \mathrm{~g}$ in an irreversible step.

Similar reactions, i.e., formation of allyl chlorides at -78 ${ }^{\circ} \mathrm{C}$ and rearrangement to cyclic vinyl chlorides at elevated temperature, are observed when propargyl chloride $1 \mathrm{c}$ is combined with 1,3-butadiene, piperylene, and 2,3-di-

(2) Typical procedure: $\mathrm{ZnCl}_{2}(1.1 \mathrm{~g})$ was dissolved in $1.3 \mathrm{~mL}$ of ether diluted with $23 \mathrm{~mL}$ of $\mathrm{CH}_{2} \mathrm{Cl}_{2}$ and cooled to $-78^{\circ} \mathrm{C}$. A solution of 3.57 $\mathrm{g}(20.0 \mathrm{mmol})$ of $1 \mathrm{c}$ and $1.36 \mathrm{~g}(20.0 \mathrm{mmol})$ of $(E)-1,3$-pentadiene in 10 $\mathrm{mL}$ of $\mathrm{CH}_{2} \mathrm{Cl}_{2}$ was added dropwise with stirring. After $4 \mathrm{~h}\left(-78^{\circ} \mathrm{C}\right)$ the catalyst was washed out with concentrated ammonia and the organic phase was dried over $\mathrm{CaCl}_{2}$. Distillation yielded $70 \% \mathrm{C}_{16} \mathrm{H}_{19} \mathrm{Cl}$. A similar procedure has been used for other cationic addition reactions: (a) Mayr, H.; Halberstadt, I. K. Angew. Chem., Int. Ed. Engl. 1980, 19, 814. (b) Mayr, H.; Seitz, B.; Halberstadt-Kausch, I. K. J. Org. Chem. 1981, 46, 1041.

(3) For 2g: ${ }^{1} \mathrm{H}$ NMR $\left(\mathrm{CCl}_{4}\right) \delta 1.29\left(\mathrm{~s}, 6 \mathrm{H}, \mathrm{CH}_{3}\right), 1.92\left(\mathrm{br} \mathrm{s}, \mathrm{CH}_{3}\right), 2.23$ (br s, 4- $\left.\mathrm{H}_{2}\right), 4.05\left(\mathrm{~d}, J=8 \mathrm{~Hz}, \mathrm{CH}_{2} \mathrm{Cl}\right), 5.53(\mathrm{br} \mathrm{t}$, vinul- $\mathrm{H}), 7.25\left(\mathrm{~m} \mathrm{C}_{6} \mathrm{H}_{5}\right)$

(4) For 9: mp 37-38 ${ }^{\circ} \mathrm{C}$; IR (neat) $1670 \mathrm{~cm}^{-1},{ }^{1} \mathrm{H}$ NMR (CCl) $\delta 0.91$ $\left(\mathrm{s}, \mathrm{CH}_{3}\right), 1.03\left(\mathrm{~s}, \mathrm{CH}_{3}\right), 1.66\left(\mathrm{br} \mathrm{s}, \mathrm{CH}_{3}\right), 1.85\left(\mathrm{br} \mathrm{s}, 6-\mathrm{H}_{2}\right), 2.85\left(\mathrm{br} \mathrm{s}, 3-\mathrm{H}_{2}\right)$ 3.38 (dd, $J=8 \mathrm{~Hz}, J=6 \mathrm{~Hz}, \mathrm{H}-4), 5.37$ (br s, H-2), 7.15-7.55 (m, $3 \mathrm{H}$, $\left.\mathrm{C}_{6} \mathrm{H}_{5}\right), 7.8-8.1\left(\mathrm{~m}, 2 \mathrm{H}, \mathrm{C}_{6} \mathrm{H}_{5}\right)$.

(5) (a) It is possible that the small amount of cyclic product 8, formed at $-78^{\circ} \mathrm{C}$, is due to reaction of allenyl cations with the s-cis dienes. (b) $\mathbf{5 g}$ is not necessarily an intermediate; triple bond participation in solvolysis of $6 \mathbf{g}$, yielding $7 \mathbf{g}$ directly, is quite possible: Stang, P. J.; Rappoport Z.; Hanack, M.; Subramanian, L. R. "Vinyl Cations"; Academic Press New York, 1979; p 123-147.
Table II. Solvoly sis Constants of Unsaturated Alkyl Halides in $80 \%$ Ethanol at $25{ }^{\circ} \mathrm{C}$

\begin{tabular}{llc}
\hline & $k_{1}, \mathrm{~s}^{-1}$ & ref \\
\hline $\mathrm{HC}=\mathrm{C}-\mathrm{C}\left(\mathrm{CH}_{3}\right)_{2} \mathrm{Cl}$ & $2.4 \times 10^{-7}$ & 6 \\
$\mathrm{H}_{2} \mathrm{C}=\mathrm{CHCH}\left(\mathrm{CH}_{3}\right) \mathrm{Cl}$ & $4.9 \times 10^{-7}$ & 7 \\
$\mathrm{CH}_{3} \mathrm{CH}=\mathrm{CHCH} \mathrm{Cl}_{2} \mathrm{Cl}$ & $1 \times 10^{-6}$ & $a$ \\
$\left(\mathrm{CH}_{3}\right)_{2} \mathrm{C}=\mathrm{CHCH}_{2} \mathrm{Cl}$ & $4 \times 10^{-4}$ & $b$ \\
$\mathrm{CH}_{3} \mathrm{C}=\mathrm{CC}\left(\mathrm{CH}_{3}\right)_{2} \mathrm{Cl}$ & $5.1 \times 10^{-4}$ & 6 \\
$\left.\mathrm{CH}_{3} \mathrm{CH}=\mathrm{CHCH}_{2} \mathrm{CH}{ }_{3}\right) \mathrm{Cl}$ & $3.8 \times 10^{-3}$ & $c$ \\
${\mathrm{PhC}=\mathrm{CC}\left(\mathrm{CH}_{3}\right)_{2} \mathrm{Cl}}_{\left(\mathrm{CH}_{3}\right)_{2} \mathrm{C}=\mathrm{CHCH}\left(\mathrm{CH}_{3}\right) \mathrm{Cl}}$ & $\approx 4 \times 10^{-3}$ & $d$ \\
& & $e$
\end{tabular}

$a, b$ Estimated from the rate of 3-chloro-1-butene by using the rate ratio of $2.1^{a}$ and $760^{b}$ calculated for $80 \%$ ethanol (ref 8). c Calculated from data in ref 9 by using the $\mathrm{mY}$ equation. $d$ Estimated from the rate of 4-chloro4-methyl-1-pentyne, assuming that replacement of alkyl by phenyl accelerates by a factor of 14.4 , as observed for solvolyses of chloroallenes (ref 10). e Estimated from rate of 4-chloro-2-pentene and the rate ratio of the corresponding allyl bromides (1133) in $80 \%$ ethanol (ref 11).

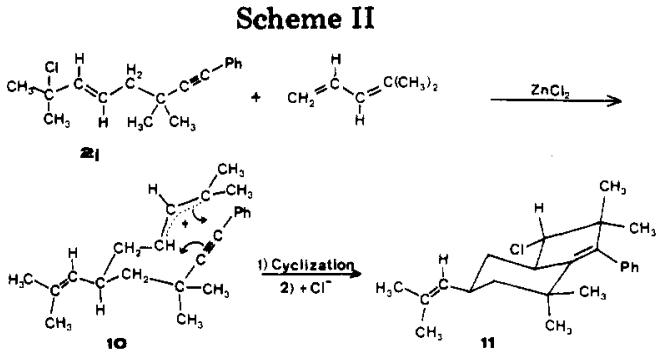

methylbutadiene. However, 1:1 addition products are not obtained from the reactions of 1c with 4-methyl-1,3-pentadiene and 2,4-dimethyl-1,3-pentadiene (Table I). An explanation for these results comes from the data in Table II. Propargyl halide 1c dissociates faster than terminally mono- and dialkylated allylic systems, which are formed from isoprene and the first three dienes. Therefore, these addition reactions terminate at the $1: 1$ product stage, as predicted previously. ${ }^{1}$ From 4-methyl-1,3-pentadiene and 2,4-dimethyl-1,3-pentadiene, tri- and tetraalkylated allylic systems are produced. These dissociate faster than 1c, resulting in the formation of polymers or of higher adducts. ${ }^{1}$ A similar situation is encountered in additions of the trimethylpropargyl chloride $1 \mathrm{~b}$ : whereas moderate yields of $1: 1$ products are obtained with butadiene and isoprene, only high molecular weight compounds are produced from 4-methyl-1,3-pentadiene. Isoprene gives lower yields of 1:1 products with $1 \mathrm{~b}$ than with $1 \mathrm{c}$ since the solvolysis rates of 1,1-dialkylallyl chlorides and $1 \mathrm{~b}$ are closely similar (Table II).

As expected from Table II, the slowly ionizing dimethylpropargyl chloride 1a does not give 1:1 products with any of the dienes investigated. At low temperature, isomerization of 1a to 1-chloro-3-methyl-1,2-butadiene and at higher temperature, polymerization of the reactants were observed.

The failure to observe 1:1 products from 4-methyl-1,3pentadiene with any of these propargyl halides is not due to Lewis acid initiated polymerization of the diene. Formation of $2: 1$ product $11^{12}$ in $23 \%$ yield (Scheme II) supports our interpretation of these reactions. The initially formed $1: 1$ product $2 j$ (trialkylated allyl chloride) dissociates faster than $1 \mathrm{c}$ and therefore reacts with further diene to give allyl cation 10. Intramolecular cycloaddition, obviously faster than intermolecular sequence reactions, yields a secondary carbenium ion, which is trapped by $\mathrm{Cl}^{-}{ }^{13}$ Since secondary alkyl chlorides dissociate more 
slowly than $1 \mathrm{c}, 11 \mathrm{can}$ be isolated as a reaction product.

Acknowledgment. We thank the Deutsche Forschungsgemeinschaft and the Fonds der Chemischen Industrie for financial support.

Registry No. 1a, 1111-97-3; 1b, 999-79-1; 1c, 3355-29-1; (E)-2c, 78739-45-4; $(Z)-2 c, 78739-46-5 ;$ 2d, 78739-47-6; $(E)-2 f, 78739-48-7$ (Z)-2f, 78739-49-8; 2g, 78739-50-1; (E)-2h, 78739-51-2; (Z)-2h, 78739-52-3; 2i, 78739-53-4; 8g, 78739-54-5; 8i, 78739-55-6; 9, 7873956-7; 11, 78739-57-8; 1-chloro-3-methyl-1,2-butadiene, 27822-67-9; zinc chloride, 7646-85-7; 1,3-butadiene, 106-99-0; 4-methyl-1,3-pentadiene, 926-56-7; isoprene, 78-79-5; (E)-1,3-pentadiene, 2004-70-8; 2,3-dimethyl-1,3-butadiene, 513-81-5; 2,4-dimethyl-1,3-pentadiene, 1000-86-8.

(6) Burawoy, A.; Spinner, E. J. Chem. Soc. 1954, 3752

(7) Grunwald, E.; Winstein, S. J. Am. Chem. Soc. 1948, 70, 846

(8) Streitwieser, A., Jr. "Solvolytic Displacement Reactions", McGraw-Hill: New York, 1972; p 78.

(9) Griffin, R. H.; Jewett, J. G. J. Am. Chem. Soc. 1970, 92, 1104.

(10) Schiavelli, M. D.; Gilbert, R. P.; Boynton, W. A.; Boswell, C. A. J. Am. Chem. Soc. 1972, 94, 5061

(11) Kiefer, E. F.; Roberts, J. D. J. Am. Chem. Soc, 1962, 84, 784

(12) The structure of 11 is based on the $200-\mathrm{MHz}^{1} \mathrm{H}$ NMR spectrum which could be solved by a first-order analysis. We thank Professor $E$. Vilsmaier, Universităt Kaiserslautern, for carrying out decoupling experiments

(13) $[3+2]$ Cycloadditions of allyl cations to alkynes have previously been reported: Miller, A.; Moore, M. Tetrahedron Lett. 1980, 577.

Herbert Mayr,* Herbert Klein

Institut für Organische Chemie der Friedrich-Alexan der-Universität Erlangen-Nürnberg Henkestrasse 42 $D$-8520 Erlangen

Federal Republic of Germany Received April 8, 1981

A Combined Electrochemical/Enzymatic Method for in Situ Regeneration of NADH Based on Cathodic Reduction of Cyclic Disulfides

Summary: NADH can be regenerated in situ from NAD by a process having as first step the electrochemical reduction of the disulfide groups of lipoamide and oxidized dithiothreitol to the corresponding dithiols; the dihydrolipoamide in this mixture reduces NAD to NADH in a reaction catalyzed by lipoamide dehydrogenase.

Sir: Here we describe a method for regeneration of NADH from NAD based on the ability of a tungsten cathode to reduce stable cyclic disulfides to the corresponding dithiols selectively in neutral aqueous solutions (Scheme I). Previous work in electrochemical methods for NAD(P)H regeneration have concentrated on direct cathodic reduction $^{1-4}$ and have not been sufficiently selective for reduction at the 4-position of the nicotinamide ring to permit high turnover numbers for those cofactors. ${ }^{5}$ In the method reported here, the electrochemical step is reductive

(1) Dryhurst, C. "Electrochemistry of Biological Molecules"; Academic Press: New York, 1977; Chapter 9. Bresmahan, W. T.; Moiroux, J.; Samec, Z.; Elving, P. J. J. Electroanal. Chem. 1980, 116, 125-155,

(2) Aizawa, M.; Coughlin, R.; Charles, M. Biotech. Bioeng. 1976, 18 , 209-215.

(3) Aizawa, M.; Ikariyama, Y.; Suzuki, S. J. Solid-Phase Biochem. 1976, 1, 249-259.

(4) Aizawa, M.; Suzuki, S.; Kubo, M. Biochim. Biophys. Acta. 1976, 444, 886-892.

(5) The reduction step must be $>99.8 \%$ selective for a 4 -position to achieve a turnover number of 1000 .
Scheme I. NADH Regeneration Based on Electrochemical Reduction of Disulfides [Abbreviations: LipDH $=$ Lipoamide Dehydrogenase

L-LDH = L-Lactate Dehydrogenase, DTT = Dithiothreitol, Lip = Lipoamide $\left.\left(\mathrm{R}=\mathrm{CH}_{2} \mathrm{CH}_{2} \mathrm{CH}_{2} \mathrm{CH}_{3} \mathrm{CONH}_{2}\right)\right]$

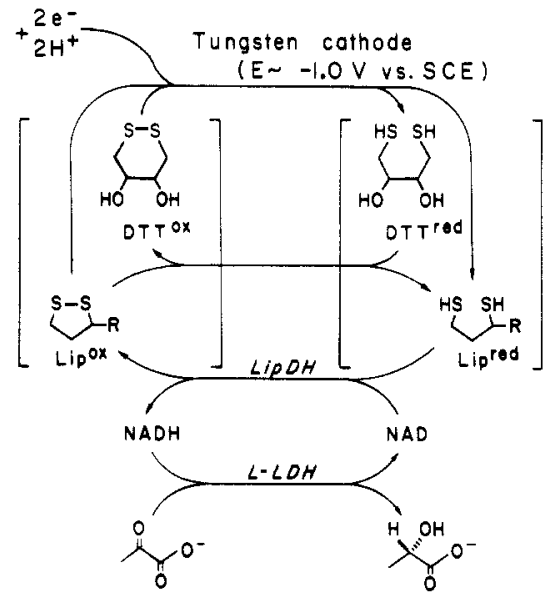

cleavage of a disulfide bond; the reduction of NAD to NADH occurs in a subsequent, regiospecific, enzymatic step. It is, of course, important that the rate of the cathodic reduction of the disulfide group(s) be much faster than the rate of any direct competing cathodic reduction of NAD, but in practice, this type of selectivity seems to be more easily achieved than that required in discriminating between positions in the nicotinamide ring.

Scheme I is based on the capability of a tungsten cathode to reduce even very stable cyclic disulfides in neutral aqueous solution without corrosion, excessive $\mathrm{H}_{2}$ production, or unacceptable rates of reduction of NAD. ${ }^{6}$ In particular, D,L-6,8-thioctic acid amide (D,L-lipoamide, Lip), D,L-6,8-thioctic acid (D,L- $\alpha$-lipoic acid), and trans-4,5-dihydroxy-1,2-dithiane (oxidized dithiothreitol, DTT ${ }^{\text {ox }}$ ) are reduced quantitatively ${ }^{7}$ to the corresponding dithiols at potentials of -1.0 to $-1.5 \mathrm{~V}$ (vs. SCE) with current efficiencies of $>80 \%$. Scheme I should not be interpreted as implying an electron-transfer mechanism for the reduction; in fact, we hypothesize that surface tungsten hydrides are the actual reducing species. The reaction does not, however, proceed by electrochemical production of $\mathrm{H}_{2}$ followed by subsequent tungsten-catalyzed reduction of the disulfides. Tungsten in not a catalyst for this reduction: no reaction occurs when disulfides are exposed to $\mathrm{H}_{2}$ in the presence of tungsten in the absence of an applied voltage.

Cyclic voltammetry shows a broad, apparently irreversible wave for reductions of these disulfides. In the presence of the concentrations of thiols and disulfides used

(6) Several groups have reported the reduction (in $\mathrm{H}_{2} \mathrm{O}$ ) of lipoic acid at a DME but have not identified the products. Patriarche, G. J.; Vire, J. C.; Mairesse-Ducarmois, C. A.; Vandenblack, J. L.; Christian, G. D. J. Electroanal. Chem. 1979, 104, 147-153. B. Nygard, Arkiv. Kemi 1967, 75-88, 89-97. Sawyer reports no reduction of the disulfide bond of lipoic acid derivatives at a gold electrode at $-2.0 \mathrm{~V}$ (SCE) (Howie, J. K.; Houts, J. J.; Sawyer, D. T. J. Am. Chem. Soc. 1977, 99, 6323-6326), and we observe no reduction at platinum. We find that reduction of $\mathrm{Lip}^{\mathrm{ox}}$ at a mercury pool or lead cathode occurs at $-2.0 \mathrm{~V}$ (SCE), and that the product reduces Eilman's reagent, but that it is not a substrate for LipDH and that it does not match authentic Lipred in HPLC retention time. Treatment of this product with DTT Trod releases Lipred. We suggest that it is a mercury(II) thiolate complex of Lip rod having high stability. Since chelating dithiols have very high association constants with $\mathrm{Hg}$ (II) (log $K=41$ for 1,3-dithiopropanesulfonic acid: Perrin, D. D. "Stability Constants of Metal-Ion Complezes"; Pergamon Press: Oxford, 1979; Part B) such stability is not surprising.

(7) The conversion of disulfides to dithiols was quantitative using assays based on Ellman's reagent, HPLC, and activity as substrate for LipDH. 